\title{
Landscape Ecology Perspective in Restoration Projects for Biodiversity Conservation: a Review
}

\author{
Melina de Souza Leite*, Leandro Reverberi Tambosi, Isabella Romitelli \& Jean Paul Metzger
}

Departamento de Ecologia, Universidade de São Paulo - USP, São Paulo, SP, Brasil

\begin{abstract}
There is good evidence that the results of a restoration program depend largely on the landscape context such as habitat cover, connectivity and isolation. Such evidence, however, is not coherently presented in the scientific literature. This review aims to provide an overview of how landscape ecology has been used in restoration projects in the last 15 years. We found only 54 empirical restoration studies published in international journals from 1997 to 2011 that used a landscape approach, mostly published between 2009 and 2011. The majority of the studies were carried out in temperate zones and forests, with habitat loss and fragmentation as the major disturbance factor (77\%). Biotic manipulation was the most common management protocol (39\%), followed by abiotic manipulation, land abandonment, and control of disturbance sources. Most of the studies (84\%) demonstrate that the landscape context plays an important role in restoration processes. Particularly, a positive influence of the landscape context on restoration effectiveness was observed for restored areas in close proximity to neighboring patches and in landscapes with high habitat cover. However, we found that the effect of landscape characteristics on restoration outcomes may vary with species characteristics, and differ according to the population or community parameters (e.g. abundance, richness, composition) considered. In addition, different landscape aspects mediated the effects of restoration on biological communities, and thus there is not a unique set of landscape indices that can be universally used for restoration planning and monitoring. Although the literature has important gaps, since most studies are restricted to few habitat and disturbance types and consider only a limited set of landscape attributes, our findings demonstrate that landscape characteristics can be as important as local factors in influencing restoration outcomes and should be incorporated in restoration projects and programmes. By considering a wide range of landscape resilience and disturbance condition since the beginning of future restoration plans, we expect that the main gaps of knowledge identified here can be filled in the near future, helping then to reveal a more general pattern relating landscape structure to restoration outcomes.
\end{abstract}

Key words: Landscape Resilience, Landscape Structure, Restoration Strategies, Disturbance.

\section{Introduction}

The mutualistic links between landscape ecology and restoration ecology became solid in the mid 1990s (Naveh 1994; Hobbs \& Norton 1996; Aronson \& Le Floc'h 1996; Bell et al. 1997). Those authors suggested that the success of a restoration action depends on the landscape context, as the processes that create and maintain restored areas are influenced by ecological and cultural dynamics at larger, landscape-level scales (Naveh 1994). Further, restoration actions can provide unique opportunities to test the effects of spatial patterns on ecological processes at larger scales (Bell et al. 1997), which is the main objective of landscape ecology (Turner 1989).

*Send correspondence to: Melina Leite

Departamento de Ecologia, Universidade de São Paulo - USP,

Rua do Matão, 321, Travessa 14, CEP 05508-090, São Paulo, SP, Brasil

E-mail: melina.leite@ib.usp.br
Along with the growing association between restoration ecology and landscape ecology came the recognition that factors that impede restoration success, previously known to exist at local scales (Suding et al. 2004; Briske et al. 2008), are also operating at larger scales (Holl \& Aide 2011). When focusing on biodiversity conservation, these large-scale restoration constraints may be related to low habitat cover and connectivity and a high degree of isolation of the restored area, which has been shown to affect the system resilience and the restoration outputs (Holl \& Aide 2011). This represents a shift in the view of local site-by-site restoration action to a larger and multiple scale perspective (Naveh 1994; Hobbs \& Norton 1996; Bell et al. 1997).

The fact that landscape characteristics can affect ecological processes and species distributions, especially in fragmented landscapes (Metzger et al. 2009; Banks-Leite et al. 2011; Martensen et al. 2012), is also relevant for restoration 
actions focused on biodiversity conservation. It particularly happens when we consider spatial attributes that regulate landscape connectivity (the capacity of landscapes to facilitate biological fluxes, such as animal movements, and pollen and seed dispersal; Taylor et al. 1993). Landscape characteristics as habitat isolation, the presence of corridors and matrix permeability are known to affect landscape connectivity (Boscolo et al. 2008; Martensen et al. 2008; Uezu et al. 2008), which can influence (re)colonization dynamics (Jacquemyn et al. 2003), and thus restoration effectiveness (Rodrigues et al. 2009).

Recent studies suggest that landscape structure, essentially landscape cover and connectivity, can be related to landscape resilience (the capacity of landscapes to recover from local species losses through immigration at larger spatial scales; Tambosi et al. 2014) and management effectiveness (Tscharntke et al. 2005; Pardini et al. 2010). These authors suggest that the best cost/benefit ratios of a restoration action for biodiversity conservation occur in landscapes characterized by intermediate levels of resilience, i.e. intermediate habitat amount that still maintain a certain level of connectivity. These landscapes shelter high levels of biodiversity, which has the potential to recolonize restored areas. However, landscapes with intermediate levels of resilience are also at higher risk for species extinctions from habitat loss and fragmentation (Pardini et al. 2010; Martensen et al. 2012). When resilience is high, i.e. with high habitat cover and connectivity, landscapes have high potential to maintain biodiversity and to recover by autogenic processes, reducing the need for investments in restoration actions (Hobbs 2007). When resilience is too low, i.e. low habitat cover and connectivity, the cost of restoration might be too large and the probability of getting any conservation benefit would be very low due to the large proportion of species loss and the low probability of recolonization. This association of landscape cover and connectivity with biodiversity conservation and landscape resilience has great potential to help restoration practitioners distinguishing areas that would most benefit from restoration actions from those that are capable of recovering without intervention (Hobbs 2007).

Although some studies have recognized the importance of large-scale processes in restoration, there are few large-scale manipulative studies (Holl et al. 2003) and few restoration projects that have adopted a landscape perspective (but see Stanturf et al. 2012). The relationship between landscape structure and restoration effectiveness can be influenced by several factors, such as the type of habitat that was restored, land use history, the frequency and intensity of disturbance, the system resilience, the management protocol, and the method used to associate landscape structure to restoration outcomes.

In order to provide an overview of how landscape ecology has been incorporated in ecological restoration projects, we performed a literature review to explore the effects of landscape characteristics on restoration outcomes. Although restoration ecology is a practical and multidisciplinary science with many objectives based on ecological, social, economic and cultural values (Clewell \& Aronson 2013), we are here basically interested in the effects of restoration actions for biodiversity conservation, rather than on ecosystem services (Chazdon 2008; Rey Benayas et al. 2009) or on socioeconomic or public policy aspects (e.g., Aronson et al. 2010). We analyzed four groups of restoration attributes, which can affect the relationship between landscape structure and restoration outputs: (1) environmental conditions of restored landscapes; (2) disturbance characteristics; (3) restoration strategy and monitoring methods; and (4) methodological procedures to analyze how landscape structure influences the restoration effectiveness. We also investigated when landscape structure is more important for restoration effectiveness. According to Tambosi et al. (2014), in intermediate resilience landscapes we expect that the influence of the landscape context on the restoration outcome is easily detected. In extreme scenarios of landscape resilience, the landscape structure would not be so important, because at one extreme recolonization and regeneration is high and is not limiting organism flow, and at the other extreme, landscape connectivity is so low that it impedes recolonization.

\section{Methods}

We performed a survey for scientific articles in the Web of Science (Science Citation Index Expanded database, http:// portal.isiknowledge.com/) and Scopus (Life Science database, http://www.scopus.com), using the keywords "landscape AND ecolog* AND restor*" in title, abstract and keyword fields. We limited the search period to between 1997 and 2011 because we consider the studies from the mid-1990s to represent the first insights on the application of landscape ecology principles to restoration. We also limited the search for scientific articles (avoiding grey literature, e.g. technical reports) not only due to access facility but also to consider more consolidated concepts and focus on results that had been peer-reviewed.

All the papers' abstracts were first evaluated to classify the study in one of the five main categories of landscape application to restoration: i) methodological; ii) conceptual contribution; iii) landscape recognition: landscape structure is not considered when planning or evaluating restoration outputs, but its importance is qualitatively recognized; iv) landscape assessment (LA): restoration is performed locally, but the outcomes are evaluated $a$ posteriori based on the landscape structure; and v) landscape restoration (LR): the restoration is performed in large, heterogeneous areas, taking into consideration both landscape structure and dynamics. In the LA class, studies were also classified as passive (LAp) or active (LAa) restoration actions (sensu Holl \& Aide 2011). Passive restoration studies are those characterized by very low human intervention such as regeneration of abandoned or degraded agricultural areas or removing/controlling disturbances in order to allow for 
natural recovery. In contrast, active restoration studies involve more intensive human mediation on the restoration process.

Afterwards, all applications (LA and LR) were surveyed in order to collect information related to the four main groups of landscape/restoration attributes we had selected (see Table 1 for a detailed description), namely (A) environmental conditions of landscapes undergoing restoration: continent, climate and type of restored habitat; (B) disturbance characteristics: previous land use, disturbance type, intensity and frequency; (C) restoration strategy and monitoring methods: restoration strategy, type and number of reference systems, method used to measure restoration success, restoration age, monitoring frequency, monitoring parameters and restoration results; and (D)

Table 1. Parameters used for the analysis of landscape restoration studies and their respective descriptions/categories.

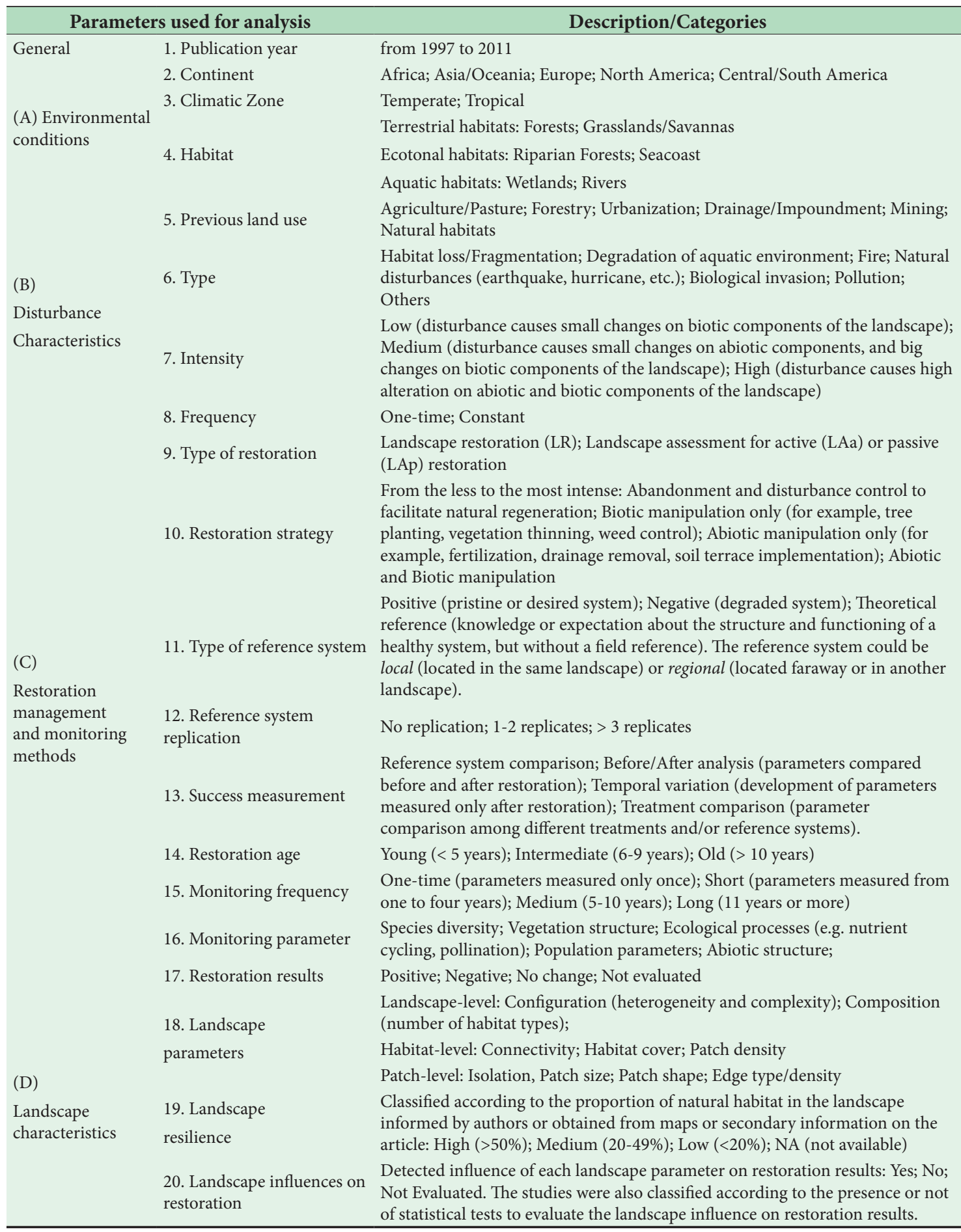


landscape characteristics: parameters considered in the analyses (divided in three levels: patch, habitat or landscape), landscape resilience based on habitat cover, and effects of landscape structure on restoration results. We classified restoration strategy (parameter 10 in Table 1) from the least to the most intensive intervention on the landscape (from abandonment and disturbance control to both biotic and abiotic manipulation). We considered biotic manipulations to be those interventions characterized by species manipulation or control (e.g. tree planting, population control, species reintroduction). Although in several cases of biotic manipulation there are also abiotic modification such as soil correction, fertilizations and shade improvements, these studies were classified as biotic manipulation. The abiotic manipulation studies were those mainly characterized by physical modification in the landscape without biotic manipulation (e.g. engineering interventions in river channels, soil reposition in query sites).

To assure consistency in all steps of the classification described above, each paper was assessed by at least two readers. When there were doubts or a lack of concurrence between readers' classification, papers were read by all authors to reach a consensus.

We analyzed whether the impact of landscape on restoration outcomes depends on the restored site's conditions. To do so, we examined whether the number of studies that detected landscape effects on restoration results was influenced by the different classes of: disturbance intensity (parameter 7 in Table 1), restoration strategy (parameter 10), monitoring parameters (parameter 16), and landscape resilience (parameter 19). We also analyzed the relationship between local disturbance intensity (parameter 9) and landscape resilience (parameter 19) in order to verify if intense local disturbances are associated with low resilience landscapes. Due to the small number of studies selected by our survey (see results), we were not able to conduct statistical analysis. Results are thus presented in number and percentages of studies $(\mathrm{N}, \%)$ by category on each item. Some items allowed more than one category per paper (e.g. type of perturbation, landscape attributes), thus, the number of cases for each category is sometimes higher than the number of studies.

\section{Results and Discussion}

\section{General patterns}

From a total of 1970 abstracts analyzed, only 254 were classified into one of the five classes of landscape application to restoration. The majority of the studies $(92 ; 36 \%)$ recognized the importance of the landscape to restoration efforts or assessment, but did not evaluate it (e.g. Burke 2001). A similar result was found by Holl et al. (2003, p. 493), in which study approximately $37 \%$ of the surveyed papers "[...] recognized the importance of large-scale ecological patterns and processes in influencing ecosystem recovery and restoration." There were 88 (35\%) methodological and $20(8 \%)$ conceptual articles, half of them being studies related to the selection of priority areas for restoration actions (e.g. Crossman \& Bryan 2006; Moreno-Mateos \& Comin 2010).

A total of 54 restoration articles (21\%) explicitly used a landscape ecology approach in empirical studies (LA or LR; list of reviewed references in supp. mat.). Even in those cases, most restoration actions were performed at a local scale and landscape characteristics were considered only when evaluating the results (LA studies; e.g. Guerrero \& Rocha 2010). This type of landscape assessment became more frequent after the year 2002 with a total of 43 articles, while landscape restoration studies (LR; e.g. Aviron et al. 2011) became more frequent only after 2007 and were reported in 11 articles (Figure 1).

More than 15 years after the insights provided in the mid 1990s on the role of landscape context in influencing restoration outcomes, the mutualistic relationships between landscape ecology and restoration ecology remain poorly explored, with few empirical studies that incorporate a landscape perspective in restoration actions. This was also found by Holl et al. (2003). Nevertheless, the great increase in empirical studies on landscape-scale restoration since 2007 shows a promising scenario for the years to come.

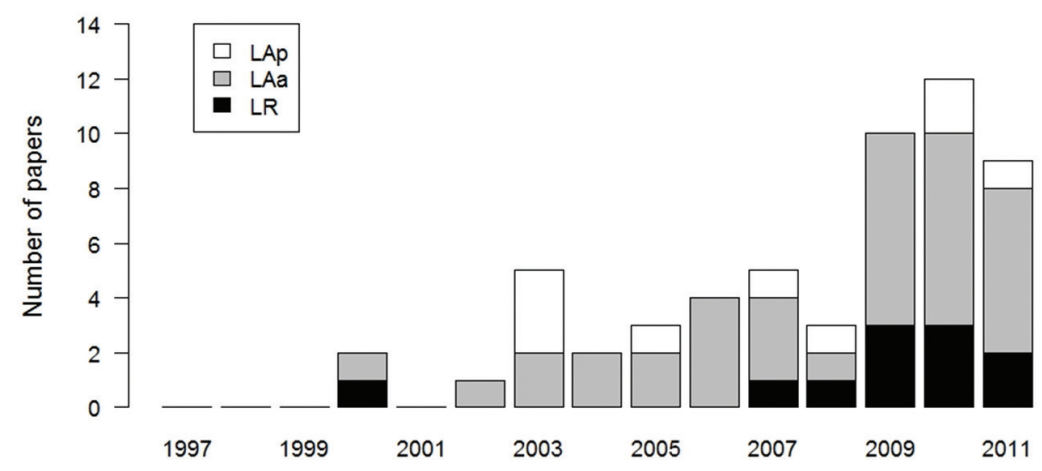

Figure 1. Number of empirical papers, per year, with a landscape restoration (LR) or with a landscape assessment for local active (LAa) and passive (LAp) restoration actions. 


\section{Characteristics of restored landscapes}

The large majority of studies was carried out in temperate zones (47; 87\%), concentrated in North America (22; 41\%), followed by Europe and Asia/Oceania (14 each; 26\% each). Only four studies were conducted in South/Central America (7\%), and there was no study recorded in Africa. Forests were by far the most frequent ecosystem type considered (forests + riparian forests, $\mathrm{N}=29$ ), followed by wetlands and grassland/savannas (Figure 2). Our results reveal a large bias in geographical distribution with most of the studies conducted in developed and temperate regions. This can be related to a publication bias (i.e., there are less academic publications in developing countries), however, it can also be an effect of the habitual time lag between the beginning of new tendencies in scientific studies and the adoption of these tendencies in developing regions (Holmgren \& Schnitzer 2004). Ruiz-Jaen \& Aide (2005) and Aronson et al. (2010) also attribute this observed geographical bias to the existence of environmental laws and funding directed to restoration projects occurring almost exclusively in developed countries. Fortunately, some initiatives are emerging in developing countries, such as in Brazil where new laws are fostering ecological restorations (Aronson et al. 2011; Brancalion et al. 2010), which can accelerate the development of restoration projects and research.

Restored landscapes were mainly modified by habitat loss/ fragmentation $\left(42 ; 78 \%\right.$ ) (Figure $S 1 a^{* *}$ ), and previously occupied by agricultural/pasture activities $(33 ; 48 \%)$ (Figure S1b). This trend was also reported by Dirzo \& Raven (2003) and Ruiz-Jaén \& Aide (2005). Forested landscapes were mostly restored with passive practices (Figure 2), which were responsible for the regeneration of temperate and tropical forests around the world (Chazdon 2008). In contrast, aquatic landscapes were frequently actively restored (Figures 2 and 3; Ruiz-Jaén \& Aide 2005), mainly because of the need to consider the whole watershed and reverse engineering modifications in order to guarantee the effectiveness of restoration (Chovanec et al. 2002; Rohde et al. 2005).

Twenty-two studies were conducted in sites under high intensity disturbance followed by 21 and 10 studies characterized by medium and low intensity disturbance, respectively. Thirty-three studies had ongoing disturbances, 19 presented one-time disturbance and two studies presented both disturbance categories.

Several authors recognize the importance of a reference system and control replications in ecological restoration projects (Ruiz-Jaén \& Aide 2005; Clewell \& Aronson 2013), and the majority of the studies $(44 ; 69 \%)$ included some kind of reference system to compare restoration outcomes (Figure 4). A large percentage of studies adopted local positive or negative references, while few used regional or theoretical references (Figure 4). There were only three studies without reference system replicates and 22 studies with more than four replicates, including eight studies that had both negative and positive local reference systems.

The large majority of studies monitored restoration only once $(36 ; 67 \%)$, followed by short $(9 ; 17 \%)$, long $(7 ; 13 \%)$, and medium (2; 4\%) monitoring frequency (Figure S2). Intermediate and old restored systems were the most frequently monitored (22 and 20, respectively) and there were only 12 studies analyzing sites less than five years after restoration (Figure S2). Despite inadequate monitoring of restored landscapes, the tendency to evaluate older restored areas ( $>10$ years) can be a valuable source of information about restoration effectiveness since the early phases of restored site might be quite different in species composition and ecological processes when compared to mature reference sites (Clewell \& Aronson 2013).

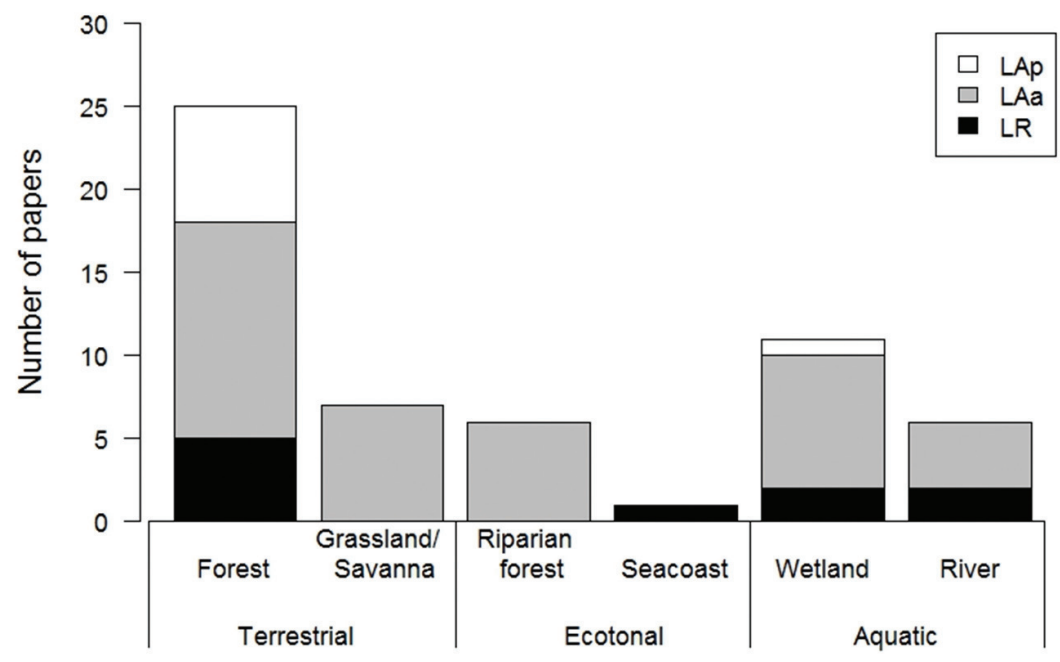

Figure 2. Restoration studies with a landscape approach (landscape restoration $=\mathrm{LR}$, landscape assessment for local passive $=\mathrm{LAp}$ or active $=$ LAa restoration actions) to different types of habitats.

${ }^{* *}$ see supplementary material available at abeco.org.br. 


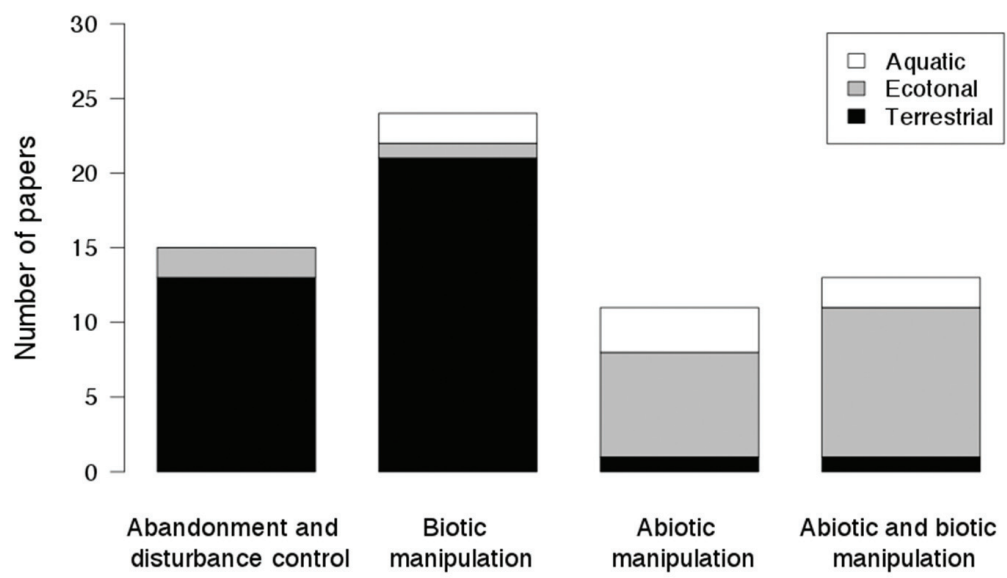

Figure 3. Number of studies in each class of restoration management according to different habitat classes.

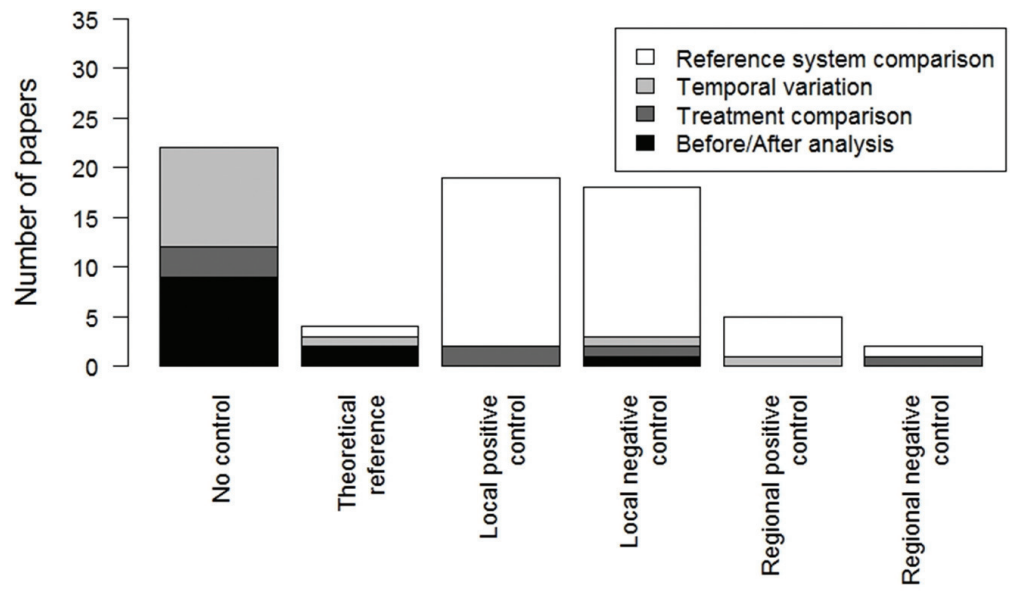

Figure 4. Relationship between reference system and success measurement in restoration studies with a landscape ecology application. For example, from the 22 studies that had no control, 9 of them used comparisons between before and after restoration to infer restoration success.

The main parameters used to monitor restoration outcomes were species diversity $(30 ; 56 \%)$, vegetation structure (27; $50 \%)$, population parameters $(16 ; 30 \%)$, followed by ecological processes $(5 ; 9 \%)$, abiotic structure evaluation (3; 6\%), community structure and landscape structure/ composition (2; $4 \%$ each). A total of $96 \%$ of the studies used at least one of the three most common parameters (Figure S3) and 18 (33\%) studies analyzed more than one parameter to evaluate restoration outcomes. The vast majority of papers evaluated the restoration outcomes as positive (47;84\%), while four studies reported no change in monitoring parameters after restoration and only one study reported negative effects after restoration.

\section{Landscape characteristics affecting restoration}

We were able to infer landscape resilience in 42 studies, and found that the majority of restoration activities were conducted in landscapes of intermediate resilience (19), followed by landscapes with low (16) and high resilience (7).
The most common landscape parameters (parameter 18, Table 1) considered in the restoration papers were related to the patch level $(78 ; 47 \%)$, followed by habitat $(46 ; 28 \%)$, and landscape $(42 ; 25 \%)$ levels (Figure 5). Two levels of landscape attributes were analyzed by 23 studies and six studies analyzed all three levels (Figure S4).

The results clearly show that landscape structural parameters at any level are important, since most part of the studies detected at least one landscape characteristic that influenced restoration outcomes (Figure S5). These findings can be biased by the tendency of publishing only significant results (Fanelli 2012). Although, in our study this bias might be lower since most of the studies tested more than one landscape parameter, with some of them affecting restoration outcomes, and others not (Figure S5). Further, even if the results are biased, the availability of studies detecting the influence of landscape structure on restoration results highlights the importance of understanding the interactions between landscape characteristics and restoration outcomes. 


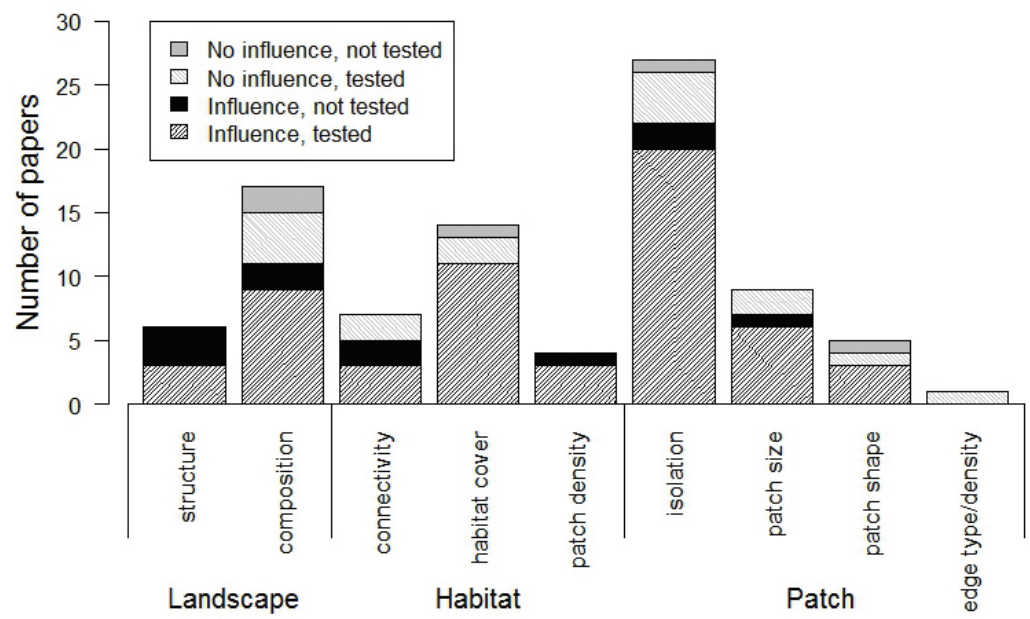

Figure 5. Frequency use of landscape parameters or indices (grouped by landscape, habitat and patch levels) and their influence (tested or not) on restoration outputs.

\section{Landscape configuration and composition}

At the landscape level, composition analyses were preferred over configuration analyses (17 and 6 studies respectively) and both influenced restoration results (Figure 5). Many studies found that more heterogeneous landscapes presented higher levels of species diversity and recolonization (Rannap et al. 2009; Gonzalez-Moreno et al. 2011; Li et al. 2011), resulting in higher improvements on species diversity in restored areas (Osland et al. 2011). Furthermore, landscapes characterized by higher percentage of agriculture can speed up vegetation succession due to high soil fertility (Matthews \& Endress 2010) if propagules sources in the landscape are not too much reduced.

\section{Habitat amount}

The habitat cover in the landscape influenced restoration outcomes in 11 of the 14 studies that analyzed this parameter. In several studies the habitat cover had a positive influence in the recolonization of restored areas by many taxonomic groups (for examples, see Munro et al. (2009) for plants; Alsfeld et al. (2010) for plants and birds; Aviron et al. (2007) for butterflies).

Restored patch size was analyzed in nine studies and was often positively related to species richness and composition (Mulhouse \& Galatowitsch 2003; Munro et al. 2009). This result could have been expected based on previous studies of species-area relationship (Watling \& Donnelly 2006). However, in some cases, the restored patch size did not influence species richness, but rather, influenced native vegetation cover (Matthews et al. 2009; Munro et al. 2009), and exotic non-native occurrence (Matthews et al. 2009), which in turn hindered recolonization by native species. Patch size was also important in influencing natural succession, with smaller restored wetlands presenting higher species turnover, probably due to high extinction probabilities in small restored areas (Matthews \& Endress 2010). Moreover, smaller patches of Pinus in Sierra Nevada presented adequate conditions to facilitate recolonization by other plant species, which was also facilitated by more irregular patch shapes (Gonzalez-Moreno et al. 2011).

\section{Edge effect}

Although edge effects are frequently addressed in conservation studies, edge parameters were assessed only once in the studies we analyzed, and did not influence restoration outcomes. However, patch shape complexity was assessed by five studies, according to which, irregular patches had higher recolonization by plants, and also higher bird species richness and reproduction (Razola \& Rey Benayas 2009; Selwood et al. 2009). Higher shape complexity might result in adequate microclimate and structural conditions for non-forest specialist species in the patch's edge (Fahrig 2003). These conditions might increase patch diversity, especially in degraded landscapes with a high number of non-forest species, since vegetation structure, microclimate conditions and availability of nesting sites can be important local limiting factors (Williams 2011).

\section{Spatial arrangement}

Patch density was assessed by four studies, and in all of them influenced restoration outcomes. Although usually associated with the deleterious effects of fragmentation, patch density (or the number of fragments) can also have a positive relationship with recolonization. For example, Thiere et al. (2009) showed higher diversity of recolonized aquatic species with higher density of wetland ponds in the landscape, probably because this higher density facilitates biological fluxes throughout the landscape. The spatial arrangement of the different landscape elements is also related to the probability of the occurrence of bird species 
(Wood et al. 2004). A spatial arrangement that does not favor landscape connectivity can limit the recolonization of restored areas as detected for birds (Razola \& Rey Benayas 2009), amphibians, invertebrates and fish species (Chovanec et al. 2002; Jähnig et al. 2009).

Connectivity was analyzed only in seven studies and did not influence restoration outcomes in two of them, although it was recognized as important in influencing several ecological processes in fragmented landscapes. This is probably due to the fact that connectivity is a species-specific measure, and is therefore difficult to take into account when monitoring several species or community responses to restoration actions.

On the other hand, patch isolation, which can be considered a more simplistic measure of the spatial arrangement of patches, and is also known to influence organismal flux in the landscape, was the most assessed landscape metric (27 studies). The isolation of restored patches affects restoration results by limiting plant, vertebrate and invertebrate recolonization in terrestrial (McLachlan \& Bazely 2003), ecotonal (Alsfeld et al. 2010), and also in aquatic habitats (Tscharntke et al. 2005). Apparently simple at a first glance, the effects of isolation can be disguised by the choice of monitoring parameters. For example, Aviron et al. (2011) did not find influence of isolation over butterfly species abundance, but the isolation influenced butterfly species richness and composition, especially when analyzing specialist species (Aviron et al. 2007).

\section{Landscape effects on restoration outputs}

Most of the studies found that the landscape characteristics influenced vegetation structure (85\%), species diversity (82\%), population parameters (62\%) and ecological processes (50\%; parameter 16 in Table 1). We found that for many studies, the same landscape characteristic can influence some monitored parameters of restoration, such as vegetation cover, while other parameters (e.g. diversity) are not affected (Jähnig et al. 2009; Alsfeld et al. 2010).

Projects that adopted land abandonment and disturbance control strategy (parameter 10) were the most influenced by landscape structure ( $92 \%$ of the studies), followed by abiotic and biotic manipulation (89\%), abiotic manipulation (78\%) and biotic manipulation projects (63\%). We consider that the small difference in landscape influence over different restoration strategies can be related to stakeholders that, empirically or intuitively, adopt management protocols and strategies adequate to the landscape characteristics. For example, land abandonment strategies are usually used in landscapes with high resilience (Lin et al. 2008; Cheung et al. 2010).

The percentage of studies reporting landscape influence on restoration outcomes tended to decrease as landscape resilience (parameter 19) increased. Parameters of landscape structure influenced restoration outcomes in $80 \%$ of the studies conducted in low resilience landscapes, followed by
$70 \%$ and $62.5 \%$ of the studies in medium and high resilience landscapes. Furthermore, landscape influence on sites with low, medium and high local disturbance was detected in $70 \%, 75 \%$ and $79.4 \%$ of the studies, respectively. All three levels of local disturbance intensities were found in all landscape resilience categories, although low resilience landscapes were mostly affected by intermediate disturbance and intermediate resilience landscapes were mainly affected by high disturbance (Figure S6).

The observed impacts of the landscape on restoration outcomes for different disturbance intensities and levels of landscape resilience were surprisingly different from what we expected. In landscapes with high local disturbance, we expected local constraints to be much more important than landscape influence. In fact, we found that local constraints were considered the only, or the most important factor in several studies (Holl \& Crone 2004; Grimbacher \& Catterall 2007; Williams 2011) but these studies were usually restricted to medium and low local levels of disturbance. However, when restoration actions were able to overcome local constraints, landscape characteristics affected restoration results, including in the more severe degradation conditions such as previous mine sites (González-Alday et al. 2009; Costa et al. 2010).

The relationship between landscape resilience and landscape influence on restoration was different from the expected by Tambosi et al. (2014). The resilience classification scheme adopted here is based on the amount of habitat cover, and is primarily supported by theoretical ideas (Andren 1994; Fahrig 2003) and empirical studies in tropical forests (Pardini et al. 2010; Martensen et al. 2012). One possible reason for the unexpected result is that resilience classes might be different for arid and semi-arid systems and for naturally fragmented habitats, such as wetlands and ponds. Beyond a potential misclassification of landscape resilience for such ecosystems, the low number of empirical restoration studies published in international journals that considered landscape structure does not allow a more robust conclusion on the effect of landscape resilience on restoration outputs.

\section{Conclusions}

To set realistic restoration goals, there are several issues that must be addressed in terms of landscape ecology and restoration ecology. This literature review shows that landscape characteristics influenced several ecological parameters that were used to monitor restoration outcomes. We also found that landscape characteristics can be as important as local site characteristics in influencing restoration effectiveness. When local limiting factor is overcome by restoration techniques, the importance of constraints at a different scale appears. Thus, both local and landscape parameters should be considered as potential constraints, which should be taken into account when planning and evaluating restoration actions. 
Our review showed that the nature of the relationship between landscape structure and restoration outputs can be much more complex than expected. Particularly, we observed unexpected results relating local disturbance and landscape resilience with restoration effectiveness, and found that the same landscape parameter can positively affect some ecological parameter and not others (e.g. patch isolation did not affect butterfly abundance but did affect its richness and community composition in restored landscapes). For such situations, it is more difficult to define an appropriate landscape structure target for restoration actions or to select a reduced number of landscape parameters as indicators to guide restoration actions. We thus still need to better understand how landscape structure affects different ecological processes associated with restoration (e.g. recolonization, recruitment, dispersion, pollination, seed dispersal) to adopt effective actions to restore degraded landscapes.

Most of the reviewed studies showed that landscape structure can play an important role in restoration outputs, and thus, we advocate that researchers and restoration managers should combine landscape and local-scale approaches when planning restoration actions. By adopting this strategy and monitoring restoration results for landscape with different resilience and disturbance levels, we will be better able to understand the intricate interactions of local and landscape factors in influencing restoration outcomes, thereby optimizing future restoration efforts.

\section{Acknowledgements}

We thank Karen Holl, James Aronson, Danielle Rappaport, Paula Lira, and Paula Prist for comments and review of the manuscript. JPM received a research fellowship and LRT received a $\mathrm{PhD}$ scholarship from $\mathrm{CNPq}$, Conselho Nacional de Desenvolvimento Científico e Tecnológico - Brazil.

\section{References}

Alsfeld AJ, Bowman JL \& Deller-Jacobs A, 2010. The Influence of Landscape Composition on the Biotic Community of Constructed Depressional Wetlands. Restoration Ecology, 18:370-378. http://dx.doi. org/10.1111/j.1526-100X.2009.00628.x

Andren H, 1994. Effects of Habitat Fragmentation on Birds and Mammals in Landscapes with Different Proportions of Suitable Habitat - a Review. Oikos, 71:355-366. http:// dx.doi.org/10.2307/3545823

Aronson J \& Le Floc'h E, 1996. Vital landscape attributes: missing tools for restoration ecology. Restoration Ecology, 4:377-387. http://dx.doi.org/10.1111/j.1526-100X.1996. tb00190.x

Aronson J et al., 2010. Are socioeconomic benefits of restoration adequately quantified? A meta-analysis of recent papers (200-2008) in Restoration Ecology and 12 other scientific journals. Restoration Ecology, 18:143-154. http://dx.doi. org/10.1111/j.1526-100X.2009.00638.x
Aronson J et al., 2011. What role should government regulation play in ecological restoration? Ongoing debate in São Paulo state, Brazil. Restoration Ecology, 19:690-695. http://dx.doi. org/10.1111/j.1526-100X.2011.00815.x

Aviron S et al., 2011. Effects of wildflower strip quality, quantity, and connectivity on butterfly diversity in a swiss arable landscape. Restoration Ecology, 19:500-508. http://dx.doi. org/10.1111/j.1526-100X.2010.00649.x

Aviron S et al., 2007. Effects of agri-environmental measures, site and landscape conditions on butterfly diversity of Swiss grassland. Agriculture, Ecosystems and Environment, 122:295-304. http://dx.doi.org/10.1016/j.agee.2006.12.035

Banks-Leite C et al., 2011. Comparing species and measures of landscape structure as indicators of conservation importance. Journal of Applied Ecology, 48:706-714. http://dx.doi org/10.1111/j.1365-2664.2011.01966.x

Bell SS, Fonseca MS \& Motten LB, 1997. Linking restoration and landscape ecology. Restoration Ecology, 5:318-323. http://dx.doi.org/10.1046/j.1526-100X.1997.00545.x

Boscolo D et al., 2008. Importane of interhabitat gaps and stepping-stones for lesser woodcreepers (Xiphorhynchus fuscus) in the Atlantic forest, Brazil. Biotropica, 40:273-276. http://dx.doi.org/10.1111/j.1744-7429.2008.00409.x

Brancalion PHS et al., 2010. Instrumentos legais podem contribuir para a restauração de florestas tropicais biodiversas. Revista Árvore, 34:455-470. http://dx.doi. org/10.1590/S0100-67622010000300010

Briske DD et al., 2008. Recommendations for development of resilience-based state-and-transition models. Rangeland Ecology \& Management, 61:359-367. http://dx.doi. org/10.2111/07-051.1

Burke A, 2001. Determining landscape function and ecosystem dynamics: Contribution to ecological restoration in the southern Namib desert. Ambio, 30:29-36.

Chazdon RL, 2008. Beyond deforestation: restoring forests and ecosystem services on degraded dands. Science, 320:14581460. http://dx.doi.org/10.1126/science.1155365

Cheung KC, Liebsch D \& Marques MCM, 2010. Forest recovery in newly abandoned pastures in southern Brazil: implications for the Atlantic Rain Forest resilience. Brazilian Journal of Nature Conservation, 8:66-70.

Chovanec A et al., 2002. Rehabilitation of a heavily modified river section of the Danube in Vienna (Austria): biological assessment of landscape linkages on different scales. International Review of Hydrobiology, 87:183-195. http:// dx.doi.org/10.1002/1522-2632(200205)87:2/3<183::AID IROH183>3.0.CO;2-R

Clewell AF \& Aronson J, 2013. Ecological restoration: principles, values, and structure of an emerging profession. Island Press.

Costa CB, Ribeiro SP \& Castro PTA, 2010. Ants as bioindicators of natural succession in savanna and riparian vegetation impacted by dredging in the Jequitinhonha River Basin, Brazil. Restoration Ecology, 18:148-157. http://dx.doi org/10.1111/j.1526-100X.2009.00643.x

Crossman ND \& Bryan BA, 2006. Systematic landscape restoration using integer programming. Biological 
Conservation, 128:369-383. http://dx.doi.org/10.1016/j. biocon.2005.10.004

Dirzo R \& Raven PH, 2003. Global state of biodiversity and loss. Annual Review of Environment and Resources, 28:137-167. http://dx.doi.org/10.1146/annurev.energy.28.050302.105532

Fahrig L, 2003. Effects of habitat fragmentation on biodiversity. Annual Review of Ecology, Evolution, and Systematics, 34:487-515. http://dx.doi.org/10.1146/annurev. ecolsys.34.011802.132419

Fanelli D, 2012. Negative results are disappearing from most disciplines and countries. Scientometrics, 90:891-904. http:// dx.doi.org/10.1007/s11192-011-0494-7

González-Alday J, Marrs RH \& Martínez-Ruiz C, 2009. Soil seed bank formation during early revegetation after hydroseeding in reclaimed coal wastes. Ecological Engineering, 35:10621069. http://dx.doi.org/10.1016/j.ecoleng.2009.03.007

Gonzalez-Moreno P et al., 2011. Is spatial structure the key to promote plant diversity in Mediterranean forest plantations? Basic and Applied Ecology, 12:251-259. http://dx.doi. org/10.1016/j.baae.2011.02.012

Grimbacher PS \& Catterall CP, 2007. How much do site age, habitat structure and spatial isolation influence the restoration of rainforest beetle species assemblages? Biological Conservation, 135:107-118. http://dx.doi.org/10.1016/j. biocon.2006.10.002

Guerrero AC \& Rocha PLB, 2010. Passive Restoration in Biodiversity Hotspots: Consequences for an Atlantic Rainforest Lizard Taxocene. Biotropica, 42:379-387. http:// dx.doi.org/10.1111/j.1744-7429.2009.00584.x

Hobbs RJ, 2007. Setting effective and realistic restoration goals: Key directions for research. Restoration Ecology, 15:354-357. http://dx.doi.org/10.1111/j.1526-100X.2007.00225.x

Hobbs RJ \& Norton DA, 1996. Towards a conceptual framework for restoration ecology. Restoration Ecology, 4:93-110. http:// dx.doi.org/10.1111/j.1526-100X.1996.tb00112.x

Holl KD \& Aide TM, 2011. When and where to actively restore ecosystems? Forest Ecology and Management, 261:1558-1563. http://dx.doi.org/10.1016/j.foreco.2010.07.004

Holl KD \& Crone EE, 2004. Applicability of landscape and island biogeography theory to restoration of riparian understorey plants. Journal of Applied Ecology, 41:922-933. http://dx.doi. org/10.1111/j.0021-8901.2004.00949.x

Holl KD, Crone EE \& Schultz CB, 2003. Landscape restoration: Moving from generalities to methodologies. BioScience, 53:491-502. http://dx.doi. org/10.1641/0006-3568(2003)053[0491:LRMFGT]2.0.CO;2

Holmgren H \& Schnitzer SA, 2004. Science on the rise in developing countries. PLoS Biology, 2:10-13. http://dx.doi. org/10.1371/journal.pbio.0020001

Jacquemyn H, Butaye J \& Hermy J, 2003. Impacts of restored patch density and distance from natural forests on colonization success. Restoration Ecology, 11:417-423. http://dx.doi.org/10.1046/j.1526-100X.2003.rec0237.x

Jähnig SC et al., 2009. Effects of re-braiding measures on hydromorphology, floodplain vegetation, ground beetles and benthic invertebrates in mountain rivers.
Journal of Applied Ecology, 46:406-416. http://dx.doi. org/10.1111/j.1365-2664.2009.01611.x

Li D et al., 2011. Patterns of waterbird community composition across a natural and restored wetland landscape mosaic, Yellow River Delta, China. Estuarine, Coastal and Shelf Science, 91:325-332. http://dx.doi.org/10.1016/j. ecss. 2010.10 .028

Lin WT et al., 2008. Eco-environmental changes assessment at the Chiufenershan landslide area caused by catastrophic earthquake in Central Taiwan. Ecological Engineering, 33:220-232. http://dx.doi.org/10.1016/j.ecoleng.2008.04.002

Martensen AC, Pimentel RG \& Metzger JP, 2008. Relative effects of fragment size and connectivity on bird community in the Atlantic Rain Forest: Implications for conservation. Biological Conservation, 141:2184-2192. http://dx.doi. org/10.1016/j.biocon.2008.06.008

Martensen AC et al., 2012. Associations of Forest Cover, Fragment Area, and Connectivity with Neotropical Understory Bird Species Richness and Abundance. Conservation Biology, 26:1100-1111. http://dx.doi. org/10.1111/j.1523-1739.2012.01940.x

Matthews JW \& Endress AG, 2010. Rate of succession in restored wetlands and the role of site context. Applied Vegetation Science, 13:346-355.

Matthews et al., 2009. Relative influence of landscape vs. local factors on plant community assembly in restored wetlands. Ecological Applications, 19:2108-2123. http:// dx.doi.org/10.1890/08-1836.1

McLachlan SM \& Bazely DR, 2003. Outcomes of longterm deciduous forest restoration in southwestern Ontario, Canada. Biological Conservation, 113:159-169. http://dx.doi. org/10.1016/S0006-3207(02)00248-3

Metzger JP et al., 2009. Time-lag in biological responses to landscape changes in a highly dynamic Atlantic forest region. Biological Conservation, 142:1166-1177. http:// dx.doi.org/10.1016/j.biocon.2009.01.033

Moreno-Mateos D \& Comin FA, 2010. Integrating objectives and scales for planning and implementing wetland restoration and creation in agricultural landscapes. Journal of Environmental Management, 91:2087-2095. http://dx.doi.org/10.1016/j. jenvman.2010.06.002

Mulhouse JM \& Galatowitsch SM, 2003. Revegetation of prairie pothole wetlands in the mid-continental US: Twelve years post-reflooding. Plant Ecology, 169:143-159. http://dx.doi. org/10.1023/A:1026221302606

Munro et al., 2009. Revegetation in agricultural areas: the development of structural complexity and floristic diversity. Ecological Applications, 19:1197-1210. http://dx.doi. org/10.1890/08-0939.1

Naveh Z, 1994. From biodiversity to ecodiversity: landscape approach conservation and restoration. Restoration Ecology, 2:180-189. http://dx.doi.org/10.1111/j.1526-100X.1994. tb00065.x

Osland MJ, Gonzalez E \& Richardson CJ, 2011. Restoring diversity after cattail expansion: disturbance, resilience, and seasonality in a tropical dry wetland. Ecological Applications, 21:715-728. http://dx.doi.org/10.1890/09-0981.1 
Pardini et al., 2010. Beyond the Fragmentation Threshold Hypothesis: Regime Shifts in Biodiversity Across Fragmented Landscapes. PLoS ONE 5: e13666. http://dx.doi.org/10.1371/ journal.pone.0013666

Rannap R, Lõhmus A \& Briggs L, 2009. Restoring ponds for amphibians: A success story. Hydrobiologia, 634:87-95. http://dx.doi.org/10.1007/s10750-009-9884-8

Razola I \& Rey Benayas JM, 2009. Effects of woodland islets introduced in a Mediterranean agricultural landscape on local bird communities. Web Ecology, 9:44-53. http://dx.doi. org/10.5194/we-9-44-2009

Rey Benayas JM et al., 2009. Enhancement of biodiversity and ecosystem services by ecological restoration: a metaanalysis. Science, 325:1121-1124. http://dx.doi.org/10.1126/ science. 1172460

Rodrigues RR et al., 2009. On the restoration of high diversity forests: 30 years of experience in the Brazilian Atlantic Forest. Biological Conservation, 142:1242-1251. http:// dx.doi.org/10.1016/j.biocon.2008.12.008

Rohde S et al., 2005. River widening: an approach to restoring riparian habitats and plant species. River Research and Applications, 21:1075-1094. http://dx.doi.org/10.1002/rra.870

Ruiz-Jaén MC \& Aide TM, 2005. Vegetation structure, species diversity, and ecosystem processes as measures of restoration success. Forest Ecology and Management, 218:159-173. http://dx.doi.org/10.1016/j.foreco.2005.07.008

Selwood K, MacNally R \& Thomson JR, 2009. Native bird breeding in a chronosequence of revegetated sites. Oecologia, 159:435-446. http://dx.doi.org/10.1007/s00442-008-1221-9

Stanturf JA, Madsen P \& Lamb D (eds.), 2012. A Goal-oriented Approach to Forest Landscape Restoration. Springer. http:// dx.doi.org/10.1007/978-94-007-5338-9

Suding KN, Gross KL \& Houseman GR, 2004. Alternative states and positive feedbacks in restoration ecology. Trends in
Ecology \& Evolution, 19:46-53. http://dx.doi.org/10.1016/j. tree.2003.10.005

Tambosi LR et al., 2014 A framework to optimize biodiversity restoration efforts based on habitat amount and landscape connectivity. Restoration Ecology. http://dx.doi.org/10.1111/ rec.12049

Taylor PD et al., 1993. Connectivity is a vital element os landscape structure. Oikos, 68:571-573. http://dx.doi. org/10.2307/3544927

Thiere G et al., 2009. Wetland creation in agricultural landscapes: Biodiversity benefits on local and regional scales. Biological Conservation, 142:964-973. http://dx.doi.org/10.1016/j. biocon.2009.01.006

Tscharntke T et al., 2005. Landscape perspectives on agricultural intensification and biodiversity - ecosystem service management. Ecology Letters, 8:857-874. http://dx.doi. org/10.1111/j.1461-0248.2005.00782.x

Turner MG, 1989. Landscape ecology - the effect of pattern on process. Annual Review of Ecology and Systematics, 20:171197. http://dx.doi.org/10.1146/annurev.es.20.110189.001131

Uezu A, Beyer DD \& Metzger JP, 2008. Can agroforest woodlots work as stepping stones for birds in the Atlantic forest region? Biodiversity and Conservation, 17:1907-1922. http:// dx.doi.org/10.1007/s10531-008-9329-0

Watling JI \& Donnelly MA, 2006. Fragments as islands: a synthesis of faunal responses to habitat patchiness. Conservation Biology, 20:1016-1025. http://dx.doi. org/10.1111/j.1523-1739.2006.00482.x

Williams NM, 2011. Restoration of nontarget species: bee communities and pollination function in riparian forests. Restoration Ecology, 19:450-459. http://dx.doi. org/10.1111/j.1526-100X.2010.00707.x

Wood DR et al., 2004. Avian community response to pinegrassland restoration. Wildlife Society Bulletin, 32:819-828. http://dx.doi.org/10.2193/0091-7648(2004)032[0819:ACRT $\mathrm{PR}] 2.0 . \mathrm{CO} ; 2$ 